\title{
To study of effective speeds for harvesting of wheat straw by straw combine
}

Ankit Kr. Upadhyay, Vivekanand Singh and Sheen C. Moses
See end of the Paper for authors' affiliation

Correspondence to :

Ankit Kr. Upadhyay

Department of Farm Machinery and Power, Vaugh School of Agricultural Engineering and Technology, Sam Higginbottom Institute of Agriculture, Technology and Sciences, Allahabad (U.P.) India
- ABSTRACT : This research study was conducted in order to determine and the performance and economic benefits of straw combine for harvesting of straw of wheat crop in combine harvested field. Straw combine are widely used for harvesting of wheat straw for small and large farm owners. Straw combine are used for straw recovered in the combine harvesting field and also recovered grains present in stubble straw of wheat crop. Today's National Green Tribunal (NGT) banned the burning of stubble straw in the field so farmers can't burn stubble straw in field. Harvesting of stubble straw is earnable and low cost process by straw combine. Three replications were taken and values of dependent variables were computed to indicate the performance and economic benefits of straw combine for harvesting of wheat straw were carried out for recovery of wheat straw w.r.t straw recovery, grain recovery, labour requirement and cost economics. The observation were taken at three speeds of $2.50 \mathrm{kmph}, 2.00 \mathrm{kmph}$ and $1.50 \mathrm{kmph}$ for straw combine at the different moisture content of 8.2 per cent, 8.6 per cent and 9.2 per cent, respectively. The analysis of data and results obtained from the evaluation of straw combine for harvesting of wheat show that the straw recovery were 89.85 per cent, 87.35 per cent and 85.74 per cent at the moisture content of 8.2, per cent 8.6 per cent and 9.2 per cent and the grain recovery were 10.13 per cent, 9.80 per cent and 9.38 per cent at the moisture content of 8.2 per cent, 8.6 per cent and 9.2 per cent, respectively. Overall results obtained from the study of straw combine for harvesting of wheat straw was time of operation, straw recovery, grain recovery, man-h/day.

- KEY WORDS : Field capacity, Field efficiency, Straw recovery, Grain recovery, Overlap percentage, Fuel consumption

- HOW TO CITE THIS PAPER : Upadhyay, Ankit Kr., Singh, Vivekanand and Moses, Sheen C. (2018). To study of effective speeds for harvesting of wheat straw by straw combine. Internat. J. Agric. Engg., 11(1) : 54-59, DOI: 10.15740/HAS/IJAE/11.1/54-59. 